\title{
TRENDS IN AETIOLOGY AND SUSCEPTIBILITY PATTERN OF BACTERIAL PATHOGENS FROM BLOODSTREAM INFECTIONS AT A TERTIARY CARE TEACHING HOSPITAL IN WESTERN MAHARASHTRA- A 4-YEAR ANALYSIS
}

\author{
Mudshingkar Swati1 ${ }^{1}$ Palewar Meghna², Dohe Vaishali3 ${ }^{3}$ Bhardwaj Renu 4 \\ ${ }^{1}$ Assistant Professor, Department of Microbiology, BJGMC, Pune. \\ ${ }^{2}$ Assistant Professor, Department of Microbiology, BJGMC, Pune. \\ ${ }^{3}$ Associate Professor, Department of Microbiology, BJGMC, Pune. \\ ${ }^{4}$ Professor and HOD, Department of Microbiology, BJGMC, Pune.
}

ABSTRACT

\section{BACKGROUND}

Bloodstream infections (BSIs) are life-threatening. Microbiological cultures take time for reporting. It is essential to start initial appropriate empirical treatment to reduce morbidity and mortality due to septicaemia. One should know the local epidemiology and susceptibility pattern of the isolates to decide appropriate empirical therapy.

\section{MATERIALS AND METHODS}

A retrospective analysis of data from blood cultures was done over a period of 4 years at a tertiary care teaching hospital. Trends in bacterial aetiology and susceptibility pattern was studied.

\section{RESULTS}

A total of 1651 bacterial isolates were obtained from 12553 blood cultures over 4-year period from 2011 to 2014 . Gram negative bacteria $(75.4 \%)$ predominated the gram-positive bacteria, $21.44 \%$ as aetiological agents of sepsis. Amongst Gram negative bacteria, E. coli in 2011 (60\%) and Klebsiella pneumonia (44\%), Citrobacter spp. (45\%) were predominant in 2012. There was emergence of Acinetobacter spp. (22\%) and Pseudomonas aeruginosa (19.5\%) as main aetiological agent of sepsis in 2012 and 2013. Analysis of Gram positive bacteria showed Staphylococcus aureus (33.3\%) as predominant aetiological agent followed by Coagulase negative staphylococci $(29.3 \%)$ and Enterococci $(26.5 \%)$. Increase in multidrug resistant pathogens was observed over the years with $60 \%$ of the isolates being MDR. The percentage of ESBL producing GNB was ranging between $60 \%$ - $62 \%$, while that of Amp C and Metallobetalactamase producers were ranging between $69 \%-71 \%$ and $13.5 \%-21 \%$ respectively. Amongst gram positive Vancomycin resistance was not seen in staphylococci, but was observed in Enterococci (2\% to 5\%). All gram positive cocci were $100 \%$ sensitive to Linezolid.

\section{CONCLUSION}

Knowing the local epidemiology and susceptibility of pathogens causing septicaemia is important to decide initial appropriate treatment in order to improve the clinical outcome of sepsis.

\section{KEYWORDS}

BSI, Gram Negative Bacteria, MDR Bacterial Infections.

HOW TO CITE THIS ARTICLE: Swati M, Meghna P, Vaishali D, et al. Trends in aetiology and susceptibility pattern of bacterial pathogens from bloodstream infections at a tertiary care teaching hospital in western Maharashtra- a 4-year analysis. J. Evolution Med. Dent. Sci. 2017;6(70):4991-4995, DOI: 10.14260/Jemds/2017/1084

\section{BACKGROUND}

As bloodstream infections (BSIs) are life-threatening, it is essential to start treatment on priority basis. Rapid immunological techniques like C-Reactive Proteins (CRP) assays may help in the preliminary diagnostic assessment of suspected septicaemia.1,2 However, they lack the capacity to detect specific pathogens. Bacteriological culture to isolate the offending pathogen remains the mainstay of definitive diagnosis of septicaemia.

Financial or Other, Competing Interest: None.

Submission 24-07-2017, Peer Review 20-08-2017,

Acceptance 26-08-2017, Published 31-08-2017.

Corresponding Author:

Dr. Mudshingkar Swati

Department of Microbiology,

B. J. Government Medical College,

Station Road, Pune-411001.

E-mail:drswati2006@gmail.com

DOI: $10.14260 /$ jemds/2017/1084
The results of bacteriological cultures and antibiotic susceptibility tests take about 3 - 4 days, necessitating initial empirical treatment of suspected septicaemia.3,4 So, knowledge of local pathogens and susceptibility pattern is important to start prompt and appropriate empirical therapy. It also helps in formulating and updating antibiotic policy.

Increasing antimicrobial resistance, changing patterns of antimicrobial usage and the wide use of indwelling catheters may change the epidemiology and outcome of bloodstream infection.

In the present study, retrospective analysis of data from blood cultures over a period of 4 years from 2011 - 2014 was done by using WHONET 5.6 software. We analysed changing trend of pathogens and their susceptibility pattern. We also studied prevalence of multidrug resistant organisms and mechanism of resistance.

\section{MATERIALS AND METHODS}

Type of Study- Descriptive study. 
Blood cultures were collected from patients with clinical signs and symptoms of sepsis. Blood cultures were collected by aseptic techniques in BACTEC blood culture bottles. Positive bottles were subcultured on Sheep blood agar and MacConkey agar and incubated at 37 degrees in $\mathrm{Co} 2$ environment. Bacterial isolates were identified by conventional microbiological techniques ${ }^{5,6}$ and antimicrobial susceptibility testing was done by Kirby Bauer disk diffusion test as per CLSI guidelines. ${ }^{7}$ The different mechanisms of drug resistance in gram negative bacteria like ESBL, Amp C and metallobetalactamases were detected by phenotypic tests as per CLSI. ${ }^{7}$ The detection of MRSA was done by using cefoxitin $30 \mathrm{mcg}$ disk. Vancomycin MIC for staphylococci was detected by using Vanco E strips (HiMedia). The Klebsiella and Esch. coli isolates were subjected to ESBL screening test with cefotaxime and ceftriaxone and confirmed by double disc potentiation test as per CLSI guidelines using ceftazidime and ceftazidime clavulanic acid. Amp C detection was done by cefoxitin screen method. Carbapenemase production in gram negative bacteria was suspected when they were resistant to carbapenems like Imipenem and Meropenem. Metallobetalactamases (MBLs) were detected by using CLSI test of Imipenem and Imipenem+ EDTA disks. A difference of more than $5 \mathrm{~mm}$ in zone diameters of both were taken as confirmed MBL producers.

Data was entered in WHONET 5.6 software and analysed to know the trend of pathogens causing BSIs and their susceptibility pattern over 4 years period.

\section{Data Analysis}

Data was retrieved from WHONET 5.6 software and analysed in same. Trends were analysed in Microsoft Excel.

\section{RESULTS}

A total of 12553 blood cultures were processed over a period of 4 years from 2011 to 2014 . Out of total, 1651 cultures were positive with positivity rate of $13.15 \%$. These positive cultures were from 1500 patients with male preponderance (56.8\%).

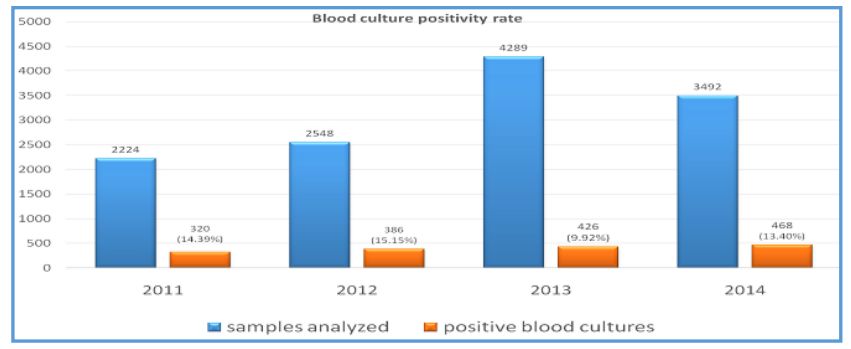

Figure 1. Blood Culture Positivity

Year wise analysis of positive blood culture showed overall positivity of $13.5 \%$. The culture positivity rate ranged from $14 \%$ in 2011 to $13 \%$ in 2014. Maximum positive blood cultures were from medical wards $(n=642)$ followed by paediatric ICU $(n=499)$, adult ICU $(n=280)$ and surgical faculty $(n=179)$.

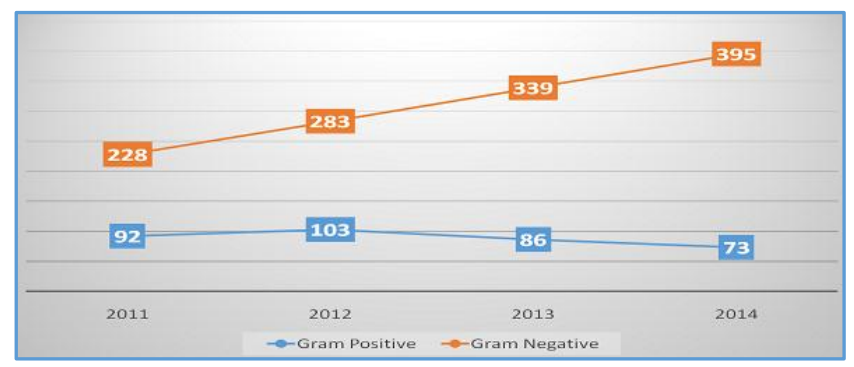

Figure 2. Trends in Aetiology of Septicaemia

When we analysed bacterial aetiology of septicaemia cases we found that Gram negative bacteria were predominant cause of bacteraemia in all 4 years in our setup. Following Fig. shows that gram negative bacteria $(n=1245)$ outnumbered gram positive bacteria $(n=354)$ as aetiological agent of septicaemia.

Amongst gram negative bacteria, E. coli was predominant in 2011. In year 2012 onwards, Acinetobacter and Pseudomonas emerged as important pathogens causing septicaemia.
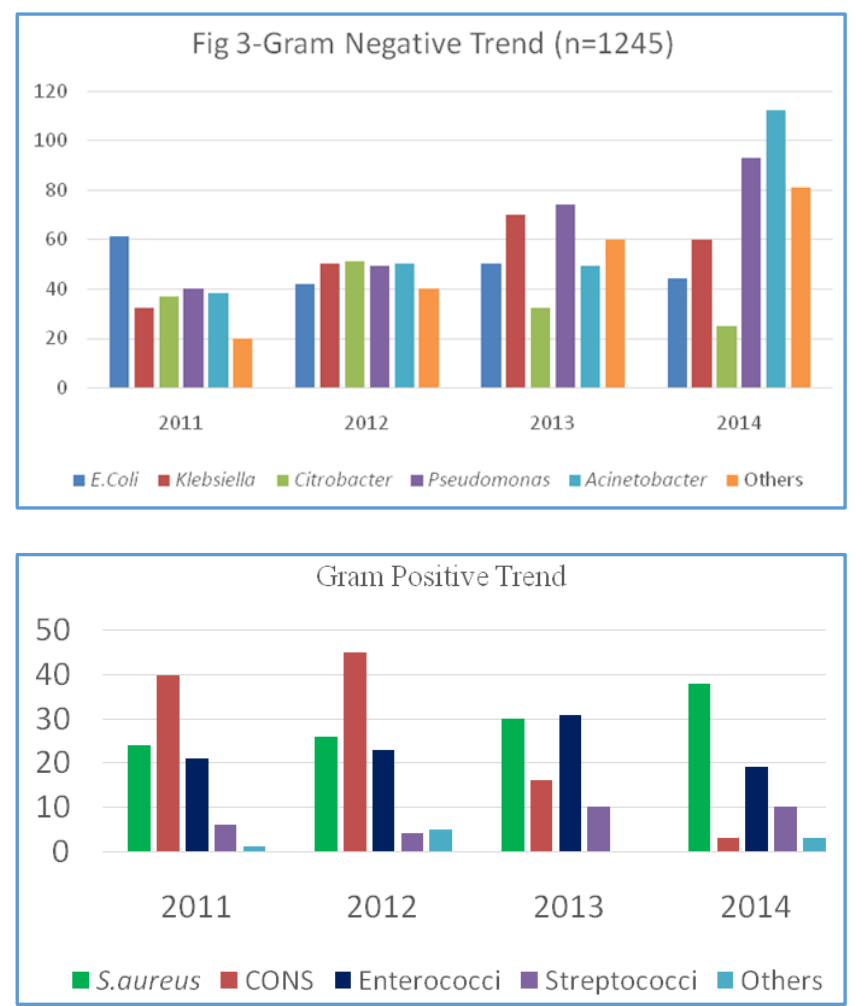

Figure 4. Amongst Gram Positive Bacteria, Staphylococci and Enterococci were Predominant Aetiological Agents in all 4 Years

Antimicrobial susceptibility pattern showed prevalence of multidrug resistant bacteria was also studied. There was increase in multidrug resistant bacteria over a period of 4 years. In gram positive cocci, percentage of MRSA has jumped from $50 \%$ to $60 \%$ in 2014 as compared to 2011 . Vancomycin resistance was observed in enterococci ranging from $2 \%$ to $5 \%$. All gram-positive cocci were $100 \%$ susceptible to vancomycin. 


\begin{tabular}{|c|c|c|c|c|}
\hline Antibiotics & $\mathbf{2 0 1 1}$ & $\mathbf{2 0 1 2}$ & $\mathbf{2 0 1 3}$ & $\mathbf{2 0 1 4}$ \\
\hline Penicillin & $24 \%$ & $13 \%$ & $13 \%$ & $27 \%$ \\
\hline Cefotaxime & $60 \%$ & $35 \%$ & $20 \%$ & $53 \%$ \\
\hline Cefoxitin & $50 \%$ & $30 \%$ & $39 \%$ & $42 \%$ \\
\hline Gentamicin & $48 \%$ & $59 \%$ & $74 \%$ & $66 \%$ \\
\hline Linezolid & $100 \%$ & $100 \%$ & $100 \%$ & $100 \%$ \\
\hline Vancomycin & $96 \%$ & $96 \%$ & $98 \%$ & $95 \%$ \\
\hline
\end{tabular}

Table 1. Percentage Susceptibility of Gram Positive Organisms $(n=354)$

Table 2. shows percent susceptibility of Gram negative organisms $(n=1245)$. Around $60 \%$ of the isolates were MDR (resistant to more than two classes of antibiotics). A total of $40 \%$ isolates were resistant to third generation cephalosporins. Resistance to carbapenems was observed.

\begin{tabular}{|c|c|c|c|c|}
\hline Antibiotics & 2011 & 2012 & 2013 & 2014 \\
\hline Amikacin & $57 \%$ & $63 \%$ & $68 \%$ & $69 \%$ \\
\hline Gentamicin & $56 \%$ & $49 \%$ & $54 \%$ & $61 \%$ \\
\hline Ciprofloxacin & $56 \%$ & $54 \%$ & $59 \%$ & $66 \%$ \\
\hline $\begin{array}{l}\text { Piperacillin/ } \\
\text { tazobactam }\end{array}$ & $51 \%$ & $39 \%$ & $66 \%$ & $68 \%$ \\
\hline Ceftazidime & $20 \%$ & $23 \%$ & $37 \%$ & $46 \%$ \\
\hline Cefotaxime & $30 \%$ & $21 \%$ & $28 \%$ & $33 \%$ \\
\hline Cefepime & $23 \%$ & $26 \%$ & $30 \%$ & $44 \%$ \\
\hline Cefoxitin & $18 \%$ & $12 \%$ & $30 \%$ & $36 \%$ \\
\hline Aztreonam & $10 \%$ & $26 \%$ & $12 \%$ & $46 \%$ \\
\hline Imipenem & $57 \%$ & $72 \%$ & $70 \%$ & $75 \%$ \\
\hline Meropenem & $70 \%$ & $25 \%$ & $54 \%$ & $69 \%$ \\
\hline Co-trimoxazole & $30 \%$ & $37 \%$ & $40 \%$ & $49 \%$ \\
\hline Colistin & $90 \%$ & $96 \%$ & $93 \%$ & $90 \%$ \\
\hline Chloramphenicol & $58 \%$ & $54 \%$ & $69 \%$ & $59 \%$ \\
\hline Tetracycline & $56 \%$ & $55 \%$ & $54 \%$ & $69 \%$ \\
\hline Polymyxin B & $90 \%$ & $99 \%$ & $94 \%$ & $86 \%$ \\
\hline \multicolumn{5}{|c|}{$\begin{array}{c}\text { Table 2. Percentage susceptibility of Gram Negative } \\
\text { Bacteria ( } n=1245)\end{array}$} \\
\hline
\end{tabular}

\section{Mechanism of Drug Resistance}

The prevalence of ESBL producers in GNB has increased from $61.6 \%$ (2011) to 66\% (2014) and that of Carbapenemase producers from $13.6 \%$ to $25 \%$. Amp C producers were ranging between $69 \%-71 \%$.

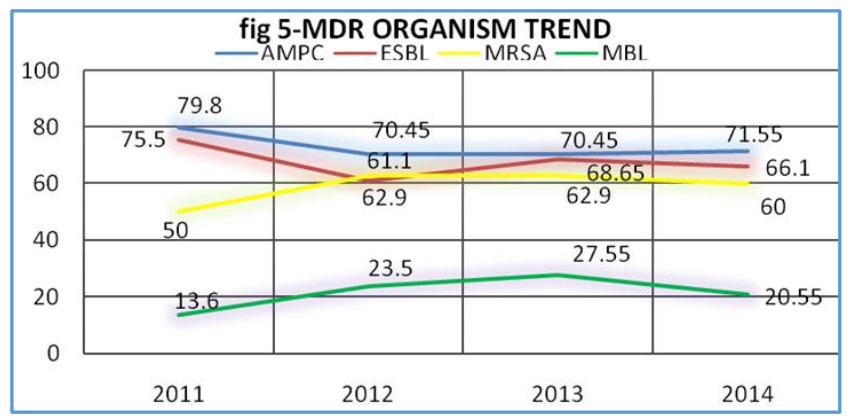

Amp C rate was highest in 2011 and was steady in next 3 yrs. ESBL rate was highest in 2011, which was followed by decline in 2012. After that it was steady at a rate of $68 \%$. MRSA prevalence was low in 2011 followed by a steady rate of $62 \%$. MBL rate has risen from $13 \%$ to $20 \%$. Peak was in 2013.

\section{DISCUSSION}

The present study demonstrated profile of microbes causing blood stream infections and their antimicrobial susceptibility pattern. There was predominance of gram negative bacteria. This finding has been observed by other recent Indian studies 2015 by Shweta Bohra et $\mathrm{al}^{8}$ and 2011 by Vanita Rani et al. $^{9}$ These authors have also noted E. coli and Klebsiella pneumoniae as predominant gram-negative bacteria causing sepsis. However, this finding is not matching with that of studies in USA ${ }^{10}$ and Ethiopia, ${ }^{2}$ where Gram positive bacteria are predominant aetiology of septicaemia. Several studies in different countries, Jimma Ethiopia, (60.9\% and 39.1\%) Gondar Ethiopia (70.2\% and 29.8\%), Zimbabwe $(71.9 \%$ and 28.1\%), Addis Ababa Ethiopia (62.6\% and 37.4\%) have shown marginally higher prevalence of Gram-positive and lower prevalence of Gram negative organisms, respectively. ${ }^{11,12,13,14}$ On the contrary, Gram-negative bacteria have been reported as the commonest cause of bacteraemia in hospitalised febrile patients in developing countries in studies conducted in Nigeria (69.3\% and 30.7\%), Saudi Arabia $(62.2 \%$ and $33.8 \%)$ and Tanzania $(69.7 \%$, $30.3 \%)^{15,16,17}$ The possible explanation for the difference could be the difference in blood culture system, the study design, geographical location, nature of patient population, epidemiological difference of the aetiological agents and seasonal variation. ${ }^{18,19}$

Amongst the gram-positive bacteria staphylococci (33.3\%), coagulase negative staphylococci (29.3\%) and enterococci (26.5\%) were predominant aetiological agents in our study. Other Indian studies have also noted the staphylococci responsible for 32\% (Shweta Bohra et al, Rajasthan, 2016) and 43\% (Vanita Rani et al, Chennai, 2011) cases of septicaemia respectively. 8,9

In the study, the prevalence of methicillin resistance in staphylococci and CONS was ranging between $60 \%$ and $62 \%$. This is high from the studies of Kamga et al, ${ }^{20}$ Kavitha et al, ${ }^{21}$ China and Gupta 22 and Karlowsky et al who reported a percentage of $18 \%, 40.8 \%, 49.5 \%$ and $29 \%$ respectively. But Garg et $\mathrm{al}^{23}$ and Kalpesh Gohel et $\mathrm{al}^{24}$ has reported $75.6 \%$ and $70 \%$ of MRSA from septicaemia, which is consistent with our findings.

In our study, all isolates of staphylococci were sensitive to vancomycin. But studies from developing countries like France (Ploy et al, 1998) and Korea (Kim et al, 1998) have reported vancomycin resistant strains of staphylococci. ${ }^{25,26}$ We observed vancomycin resistance in enterococci in the range of $2 \%$ to $5 \%$. Gohel et $\mathrm{al}^{24}$ has observed vancomycin resistance in $50 \%$ of their isolates, but number of isolates were only 4 . In contrary, Jagdish et al has not observed any resistance to vancomycin in enterococci. ${ }^{27}$ As vancomycin resistance is very low in our study, vancomycin can be safely recommended for initial empirical treatment of suspected gram-positive infections.

In the present study, 66\% MDR of GNB were MDR (resistant to more than two classes of antibiotics). But a good sensitivity was observed to Amikacin (69\%), Gentamicin (61\%), Ciprofloxacin (66\%) and piperacillin/tazobactam $(68 \%)$. So, based on these findings, a combination of piperacillin/tazobactam plus gentamicin can be recommended for initial empirical treatment. This is similar to finding by Gohel et $\mathrm{al}^{27}$ and Pavani et al. ${ }^{28}$ 
In our study, we reported high ESBL percentage ranging from $75 \%$ in 2011 , but in 2014 it was reduced to $66 \%$. This initial high ESBL percentage was attributed to rampant use of third generation cephalosporins in our institute, but it came down as we formulated and enforced our antibiotic policy in 2014. Other studies in India by Gohel et al, ${ }^{24}$ Kavitha et al ${ }^{21}$ and Arora and Devi et $\mathrm{al}^{29}$ have reported $39.6 \%, 32 \%$ and $34.4 \%$ ESBL producers respectively.

The prevalence of Amp C producing gram negative rods was found to be high in 2011 to $79.8 \%$, which later was reduced to a rate of $71 \%$ in our study. Again, reason being the strict enforcement of antibiotic policy in 2014. The high prevalence of Amp C producers could be because of Amp C and ESBL co-production, which is matching with finding by Hemlatha et al who reported $86.1 \%$ of ESBL and Amp C coproduction. ${ }^{30}$

In the present study, the percentage MBL producing bacteria is increasing from $13.6 \%$ in 2011 to $20.5 \%$ in 2014 . This could be attributable to injudicious use of carbapenems in our institute. But now we are enforcing formulary restrictions to carbapenems to bring down the rate. MBL prevalence has been reported to the rate of $9 \%$ by Naveen Kumar et $\mathrm{al}^{31}$ and $19.2 \%$ by Jayanti Jena et al. ${ }^{32}$ These findings are in accordance with our study.

All these MDR bacteria increase the morbidity and mortality due to blood stream infections. Also, they pose a great threat to infection control practices. One needs to be very vigilant while dealing with these MDR bugs. Judicious use of antimicrobials and enforcement of infection control measures are the keys to success over these bugs along with periodic surveillance of antimicrobial resistance pattern.

\section{CONCLUSION}

The present study highlights that in contrast to developed countries, gram negative rods are the leading cause of septicaemia in developing countries. Escherichia coli and Klebsiella pneumoniae were most common GNB isolated. There was emergence of hospital acquired bugs like Pseudomonas aeruginosa and Acinetobacter species. For initial empirical treatment of BSIs amikacin, piperacillin/ tazobactam and vancomycin were recommended. As MDR pathogens are on rise, the study warrants implementation of antimicrobial stewardship measures and strict enforcement of infection control practices. Epidemiological studies like the current one should be done to know the local bugs and susceptibility to start appropriate empirical antimicrobial treatment, which in turn improves the clinical outcome.

\section{REFERENCES}

[1] Meremikwu MM, Nwachukwu CE, Asuquo AE, et al. Bacterial isolates from blood cultures of children with suspected septicaemia in Calabar, Nigeria. BMC Infect Dis 2005;5:110.

[2] Dagnew M, Yismaw G, Gizachew M, et al. Bacterial profile and antimicrobial susceptibility pattern in septicemia suspected patients attending Gondar university hospital, Northwest Ethiopia. BMC Res Notes 2013;6:283.

[3] Asindi AA, Ekanem AD. Neonatal deaths in Calabar Nigeria. East Afr Med J 1988;65(5):335-41.
[4] Asindi AA, Ibia EO, Udo JJ. Mortality pattern among Nigerian children in the 1980s. J Trop Med Hyg 1991;94(3):152-5.

[5] Farmer JJ, Boatwright K, Janda M. Enterobacteraceae: introduction and identification. In: Murray P, Barron EJ, Jorgensen J, et al. (eds). Manual of clinical microbiology. 9th edn. Washington DC: American Society of Microbiology press, 2010:649-69.

[6] Forbes BA, Sahm DF, Weissfeld AS. In: Bailey and Scott's diagnostic microbiology. 12 $12^{\text {th }}$ edn. Missouri: Mosby Elsevier 2007:pp 779.

[7] Performance standards for antimicrobial susceptibility testing. Twelth international supplement. CLSI document M100-S12 [ISBN1-56238454-6]. CLSI, 940 WEST VALLEY Road, suite 1400, Wayne Pennsylvania 19087-1898 USA, 2002.

[8] Bohra S, Vyas A, Kumar M, et al. Secular trend of antibiotic resistance in blood stream infections-a retrospective analysis. Int J Curr Microbiol App Sci 2016;5(6):798-805.

[9] Rani VN, Gopal K, Narendra VM, et al. A retrospective study on blood stream infections and antibiotic susceptibility patterns in a tertiary care teaching hospital. International Journal of Pharmacy and Pharmaceutical Sciences 2012;4(1).

[10] James AK, Mark EJ, Deborah CD, et al. Prevalence and antimicrobial susceptibilities of bacteria isolated from blood cultures of hospitalized patients in the United States in 2002. Ann Clin Microbiol Antimicrob 2004;3:7.

[11] Zenebe T, Kannan S, Yilma D, et al. Invasive bacterial pathogens and their antibiotic susceptibility patterns in Jimma university specialized hospital, Jimma, South West Ethiopia. Ethiop J Health Sci 2011;21(1):1-8.

[12] Ali J, Kebede Y. Frequency of isolation and antimicrobial susceptibility pattern of bacterial isolation from blood culture, Gondar University teaching hospital, Northwest Ethiopia. Ethiop Med J 2008;46(2):155-61.

[13] Obi CL, Mazarura E. Aerobic bacteria isolated from blood cultures of patients and their antibiotic susceptibilities in Harare, Zimbabwe. Cent Afr J Med 1996;42(12):332-6.

[14] Shitaye D, Asrat D, Woldeamanuel Y, et al. Risk factors and etiology of neonatal sepsis in Tikur Anbessa university hospital, Ethiopia. Ethiop Med J 2010;48(1):11-21.

[15] Nwadioha SI, Nwokedi EOP, Kashibu E, et al. A review of bacterial isolates in blood cultures of children with suspected septicemia in a Nigerian tertiary hospital. African J Microbiol Res 2010;4(4):222-5.

[16] Elbashier AM, Malik AG, Knot AP. Blood stream infections: microorganisms, risk factors and mortality rate in Qatif central hospital. Ann Saudi Med 1998;18(2):176-80.

[17] Meremo A, Mshana SE, Kidenya BR, et al. High prevalence of non-typhoid salmonella bacteraemia among febrile HIV adult patients admitted at a tertiary hospital, North-Western Tanzania. Int Arch Med 2012;5(1):28. 
[18] Kapoor L, Randhawa VS, Deb M. Microbiological profile of neonatal septicemia in a pediatric care hospital in Delhi. J Commun Dis 2005;37(3):227-32.

[19] Diekema DJ, Beekmann SE, Chapin KC, et al. Epidemiology and outcome of nosocomial and community-onset bloodstream infection. J Clin Microbiol 2003;41(8):3655-60.

[20] Kamga HLF, Njunda AL, Nde PF. Prevalence of septicemia and antibiotic sensitivity pattern of bacterial isolates at the university teaching hospital, Yaoundae, Cameroon. African Journal of Clinical and Experimental Microbiology 2011;12(1):2-8.

[21] Kavitha P, Sevitha B, Sunil R. Bacteriological profile and antibiogram of blood culture isolates in a pediatric care unit. J Lab Physicians 2010;2(2):85-8.

[22] China D, Gupta V. Bacteriological profile and antimicrobial susceptibility pattern of blood isolates from a tertiary care hospital in North India. International Journal of Pharmaceutical Research and Bioscience 2013;2(2):24-35.

[23] Garg A, Anupurba S, Garg J. Bacteriological profile and antimicrobial resistance of blood culture isolates from a university hospital. JIACM 2007;8(2):139-43.

[24] Gohel K, Jojera A, Soni S, et al. Bacteriological profile and drug resistance patternsof blood culture isolates in a tertiary care nephrourology teaching institute. Bio Med Research International 2014;Article ID 153747:5.

[25] Kim MN, Pai CH, Woo JH, et al. Vancomycinintermediate S. aureus in Korea. J Clin Microbiol 1998;38:3879-81.
[26] Ploy MC, Grelaud C, Martin C, et al. First clinical isolate of vancomycin-intermediate staphylococcus aureus in a French hospital. Lancet 1998;351(9110):1212.

[27] Jagdish L, Naik TB, Gupta RK, et al. Etiology of blood culture from septicemia cases and their antibiotic susceptibility pattern at a tertiary care hospital. Indian J Microbiol Res 2016;3(4):435-39.

[28] Pavani G, Kommula VM, Mudaliar JLK. Bacteriological profile and multidrug resistance patterns of blood culture isolates in a teaching hospital in south India. NJIRM 2012;3(3):55-9.

[29] Arora U, Devi P. Bacterial profile of blood stream infections and antibiotic resistance pattern of isolates. JK Science 2007;9(4):186-90.

[30] Hemalatha V, Padma M, Sekar U, et al. Detection of Amp C beta lactamases production in Escherichia coli \& Klebsiella by an inhibitor based method. Indian J Med Res 2007;126(3):220-3.

[31] Naveenkumar C, Swathi S, Srikumar R. Metallo-beta lactamase (MBL) detection in multi drug resistantgram negative bacilli (MDR-GNB) isolates. Journal of Innovative Research and Solutions 2014;1(1):1-7.

[32] Jena J, Sahoo RK, Subudhi E, et al. Prevalence of ESBL, MBL and Ampc-b-Lactamases producing multidrug resistance gram negative bacteria in a tertiary care hospital. Journal of Pure and Applied Microbiology 2014;8(5):4099-105. 